\title{
Thermal Hydraulic Analysis of a Nuclear Reactor due to Loss of Coolant Accident with and without Emergency Core Cooling System
}

\author{
Pronob Deb Nath*, Kazi Mostafijur Rahman, Md. Abdullah Al Bari \\ Department of Mechanical Engineering, Khulna University of Engineering \& Technology, Khulna-9203, BANGLADESH
}

Received: June 05, 2020, Revised: June 26, 2020, Accepted: June 26, 2020, Available Online: June 29, 2020

\begin{abstract}
This paper evaluates the thermal hydraulic behavior of a pressurized water reactor (PWR) when subjected to the event of Loss of Coolant Accident (LOCA) in any channel surrounding the core. The accidental break in a nuclear reactor may occur to circulation pipe in the main coolant system in a form of small fracture or equivalent double-ended rupture of largest pipe connected to primary circuit line resulting potential threat to other systems, causing pressure difference between internal parts, unwanted core shut down, explosion and radioactivity release into environment. In this computational study, LOCA for generation III+ VVER-1200 reactor has been carried out for arbitrary break at cold leg section with and without Emergency Core Cooling System (ECCS). PCTRAN, a thermal hydraulic model-based software developed using real data and computational approach incorporating reactor physics and control system was employed in this study. The software enables to test the consequences related to reactor core operations by monitoring different operating variables in the system control bar. Two types of analysis were performed $-500 \%$ area break at cold leg pipe due to small break LOCA caused by malfunction of the system with and without availability of ECCS. Thermal hydraulic parameters like, coolant dynamics, heat transfer, reactor pressure, critical heat flux, temperature distribution in different sections of reactor core have also been investigated in the simulation. The flow in the reactor cooling system, steam generators steam with feed-water flow, coolant steam flow through leak level of water in different section, power distribution in core and turbine were plotted to analyze their behavior during the operations. The simulation showed that, LOCA with unavailability of Emergency Core Cooling System (ECCS) resulted in core meltdown and release of radioactivity after a specific time.
\end{abstract}

Keywords: LOCA; VVER-1200; PCTRAN; ECCS; Thermal-hydraulic behavior.

This work is licensed under a Creative Commons Attribution-NonCommercial 4.0 International

\section{Introduction}

VVER-1200 is the utmost type of VVER pressurizer water reactor (PWR) meaning Vodo Vodyanoi Energetichesky Reaktor or water-water energetic reactor with improved safety features design and developed by OKB Gidropress, Russia. It is a thermal neutron pressurizer reactor used water not only as coolant but also as moderator. It consists of two circuit namely the primary circuit, where the primary coolant receives heat from reactor core and the secondary circuit where the heat supplied to produce electricity [1] with four cooling loops, main circulation pump, accumulator tanks of the ECCS, relief and safety emergency valves. It's said to be a generation III+ reactor with improved safety features like sacrificial concrete core catcher layer, passive heat removal system, etc. Inside the core, the primary coolant deposit at 155 bar so that it can avoid vaporization at high temperature [2]. Any leakage in the coolant circuit can lose large amount of coolant from Reactor Cooling System (RCS) result in Design Basis Accident or Beyond Design Basis Accident according to the flow from RCS.

Design-basis accident (DBA) is a postulated accident that a nuclear facility must be designed and built to withstand without loss to the systems, structure and components necessary to ensure public health and safety. DBA concept is very feasible for abnormal operations in a nuclear power plant to vindicate performance requirements for reactor system, structure and components after anticipated operational occurrence. Beyond
Design Basis Accident (BDBA) which have extremely low probability of happening is a sequence of accident which may or may not lead to core degradations. DBA postulate for each type of reactor covering different type of failure combinations like reactivity-initiated accident, loss of flow transients, Loss of coolant accidents, fuel handling accidents and so on. The DBA is prescribed to different limiting condition for cladding temperature, local fuel cladding oxidation, $\mathrm{ZrO}_{2}$ mass cladding, whole body dose and others [3].

LOCA is one of most important and common DBAs for each reactor design depending on size of break. LOCA assumed that one of inlet or outlet pipe from circulating pump to reactor vessel completely broken or partially broken and free discharge of primary coolant from both broken ends occur. LOCA can be happening for different reasons like, material defects of different systems, material fatigue in pipe/shell, external impacts like heavy loads or missiles, device failure during operation due to different reasons, inadvertent opening on primary system boundary and so on. The nuclear reactor core has different emergency system to mitigate different type of accident depend on the incident or accident type.

There are various safety features in VVER 1200 reactor plants. VVER 1200 reactors are capable of sustaining initiating events as well as their consequence under accident conditions during a long period within the boundaries of design safety criteria and assured by following structural and design features 
like (a) increased coolant volume above the core (b) increased coolant volume in the primary circuit in respect to fuel mass and thermal power of the core (c) increased capacity of pressurizer (d) reliable natural circulation (e) considerable water inventory in horizontal SGs on the secondary side [2].

The primary coolant system of reactor core is the system which is heated at reactor core flows into steam generator. The primary coolant flow through heat exchanger tube boiling the coolant in secondary cooling system which flow outside of heat exchanger tube that drive the turbine generator and creates mechanical energy from heat energy. After that, the primary coolant comes from steam generator flow back to reactor core using compressed pump.

The leakage size within reactor coolant pressure boundary divided into two group namely Large Break Loss of Coolant Accident (LBLOCA) and Small Break Loss of Coolant Accident (SBLOCA). Reduction of water temperature during Emergency core cooling system injection drop in about $50^{\circ} \mathrm{C}-70^{\circ} \mathrm{C}$ the break can be categorized as small breaks and for large break reduction of temperature about $120^{\circ} \mathrm{C}-150^{\circ} \mathrm{C}$ [4]. The primary system remains at high pressure after the occurrence of LOCA and the core remain covered. Coolant flows inside the primary system as soon as the pumps are tripped due to automatically or manually gravity control phase separation occurrence. The next subsequent events depend on the overall behavior of the primary and secondary system. Automatic and operator-initiated mitigation measurements influenced the overall behavior. Reactor design, break size, location of the break, core bypass system, operator interactions have influenced the scenario. Each alternative action has much impact to make a huge difference on the LOCA. The LBLOCA classical DBA for reactor core where one of the inlet pipes from the circulating pump is completely non-functional or free discharge of primary coolant from both broken ends which referred as Double Ended Guillotine break. LOCA have those following phase (a)BLOWDOWN PHASE, 0-20 seconds (b) BYPASS PHASE, 20-30 seconds (c) REFILL PHASE, 30-40 seconds (d)REFLOODING PHASE, 40-250 seconds (e) LONG TERM COOLING >250 seconds.

The VVER-1200 has following active and passive system to mitigate different accident: (i) The Primary Circuit Emergency with Planned Cooldown and Spent Fuel Cooling (ii) Low Pressure Emergency Injection System to supply Boric Acid Solution (iii) Emergency Core Cooling System (iv) Passive Core Flooding System (v) Emergency Boron Injection System (vi) Emergency Gas Removal System (vii) Primary Overpressure Protection (viii) Secondary Overpressure Protection (ix) Passive Heat Removal System (x) Steam Generator Emergency Cooldown System (xi) Main Steam-line Isolation System (xii) Double Envelope Containment and Core Catcher [1].

Personal Computer Transient Analyzer (PCTRAN) is a nuclear reactor transient and accident simulation tool that operates on a personal computer for learning different nuclear reactor behavior under different condition. Concepts of neutron multiplication, criticality, thermal hydraulic safety parameters, transient analysis, accidental dose estimation and Xenon poisoning and feedback in live simulation statistical analyses can be carried out. The PCTRAN-VVER1200 simulator version 1.2.0 available from Micro-Simulation Technology for VVER1200 reactor for thermal output of $3200 \mathrm{MWt}$ with two loops of reactor coolant system represented as loop A and loop B use for the numerical simulation purpose. It has shown the major systems and components of the reactor like RCS, the Emergency Core Cooling System (ECCS), the Pressurizer with its components, the Low-Pressure Injection System (LPIS), Feed/bleed water system, Steam Generator, Accumulator, different safety valves and different components of the NPP. The components like pump, valves indicating red colored are operating and open system and white indicating colored indicate idle and closed in the mimic interactive. Those components can be switch on or off just by clicking on them in the interactive display. It has two interface, the main interface for different component and Dose mimic interface for radioactivity display.

Transient behavior simulation has been successfully benchmarked by using PCTRAN approved by International Atomic Energy Agency (IAEA). PCTRAN based on end-users input data with a reactor point kinetics model for analysis nuclear safety related concepts and phenomena that could be easily explained with the simulators along with understanding of valuable technological differences in various designs of PCTRAN products. A high-resolution color mimic of the Nuclear Steam Supply System (NSSS) and containment displays are the status of important parameters and allows simulation of operator actions by interactive control.

Though the main purpose of this simulator is operator training and a dynamic test to validate the control logics in reactor regulating system (RRS), this simulator is also used for research purposes. Like, Mollah review about PCTRAN simulator for safety and transient analysis of PWR [5]. Ibrahim et al. showed Simulation of Safety and Transient Analysis of a Pressurized Water Reactor using the PCTRAN [6]. Yi-Hsiang Cheng et al. integrated development of accident dose consequences simulation software for nuclear emergency response applications using PCTRAN software [7]. Also further they analyze the Improvement of accident dose consequences for nuclear emergency response applications using PCTRAN simulator [8]. Khan and Islam published an article on a PCTRAN based investigation on the effect of inadvertent control rod withdrawal on the thermal-hydraulic parameters of a VVER1200 nuclear power reactor [9]. Fyza et al. analyzed the thermalhydraulic parameters of VVER-1200 due to loss of coolant accident concurrent with loss of offsite power with PCTRAN and conclude with PSAR (Preliminary Safety Assessment Report) regarding LOCA [10]. Tube rupture in steam generator and transient analysis of VVER-1200 using PCTRAN simulation is conducted by Saha et al. [11].

Only a limited research works on VVER-1200 new generation III+ reactor related topic has been conducted. In this study, the thermal hydraulics behavior of VVER-1200 reactor due to LOCA with 500\% area with and without ECCS are simulated by using PCTRAN software. Thermal hydraulic parameters like, coolant dynamics, heat transfer, reactor pressure, critical heat flux, temperature distribution in different sections of reactor core have also been investigated in the simulation. The flow in the reactor cooling system, steam generators steam with feed-water flow, coolant steam flow through leak level of water in different section, power distribution in core and turbine were plotted to analyze their behavior during the operations. 


\section{Methodology}

The numerical analysis was carried out by PCTRAN VVER1200 v-1.2.0. By this software package one can simulate a variety of accident and transient condition for VVER-1200 reactor nuclear power plants. User can select initial conditions corresponding to different parameter and initiate malfunctions to analyze as desired. Following analysis had been conducted by this software- normal operating control, stream line break or LOCA, recirculation pump trip, turbine trip, station blackout, inadvertent rod withdrawal or insertion, Boron dilution transient, steam generator tube rupture, feedwater transient, anticipated transient without scram and any combination of above. The user can manually trip the reactor pump, open or close valve, override ECCS, change operational set points. The plant mimic system has the ability to freeze, back track, snap a new initial condition, change the simulation speed, trend plot by selected variable for conducting system analysis.

The simulator based on nuclear reactor theory and solution technique by Six- group point kinetics model which is a point kinetics equation with six delayed neutron groups and reactivity control from external sources and feedback. The model equations are described in the literature by A.S. Mollah [5]. The initial steady state conditions of the plant were Reactor Power at $100 \%$ with RC Pressure 155 bar and Core Average Temperature $306.9^{\circ} \mathrm{C}$ with BOC (Beginning of Cycle) of Steam Generator (SG) pressure 70 Bar. After setting up the initial and boundary conditions, the necessary operating parameters were measured for the analysis of reactor performance. Default values of VVER-1200 reactor were given which can be changed to initial value as required. Different type of malfunctions with initial value, fraction percentage, delay time will be set initially to run simulation.

After completion of simulation, transient plot of different variables like flow rate, coolant activity, concentration of materials, dose rate, fraction, energy, level of water, mass of different element, power of different system, pressure, radioactivity, enthalpy temperature, void fraction could be created with respect to time and other variables. The sequence of simulation of the whole process is shown in Fig. 1.

\section{Step 1. Set and active the simulation for run}

Step 2. Default initial condition or set new initial condition as required

Step 3. Describe malfunction with delay time and failure fraction

Step 4. Run the simulation in control panel

Step 5. View transient plot and data for different variables

Step 6. Save transient report and dose data for analysis

Fig. 1 Steps/order of simulation in PCTRAN.

\section{Computational Results and Discussion}

In this computational analysis two cases have been considered for investigation. First case accounted for a design basis loss of coolant accident where the ECCS was in operation and the second case was for a beyond design basis loss of coolant accident without any type of ECCS and passive cooling system. After conducting the computational analysis, the plot relevant to different parameters were discussed.

\subsection{Analysis of LOCA at cold leg with all ECCS}

In this simulation $500 \mathrm{~cm}^{2}(25.23 \mathrm{~cm}$ diameter $)$ break in cold leg simulation have been conducted. LOCA with break at cold leg has serious impact because safety injection system makeup water lost through this break. The simulation carried out using manually defined malfunction in the code control at cold leg with $500 \mathrm{~cm}^{2}$ failure fractions after 5 seconds of the simulator to run at steady state condition as shown in Fig. 2. To minimize the coolant loss, the RCPs manually tripped. There was a rupture icon in the cold leg with primary coolant loss rate appears in the simulator. Safety injection systems started automatically after reactor trip signal generated on because of the low pressure.

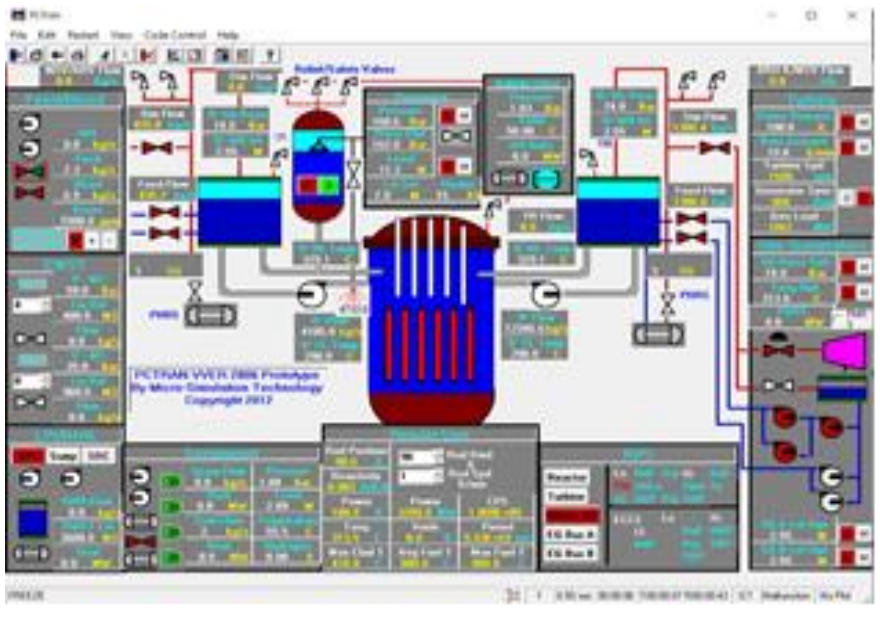

Fig. 2 Graphical user interface of PCTRAN: Initiation of 500 $\mathrm{cm}^{2}$ cold leg LOCA.

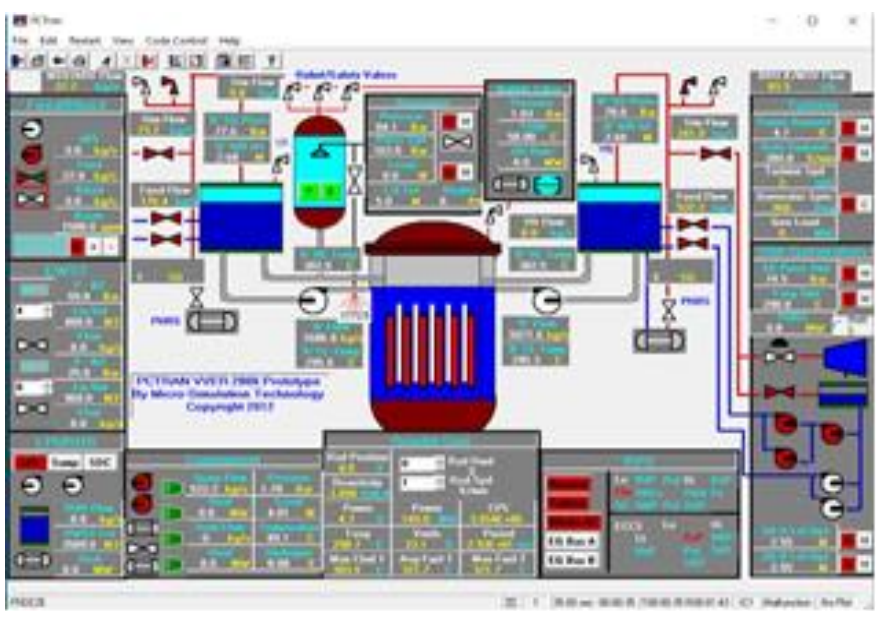

Fig. 3 Graphical user interface of PCTRAN: Reactor trip and actuation of HPIS, RB spray pump. 


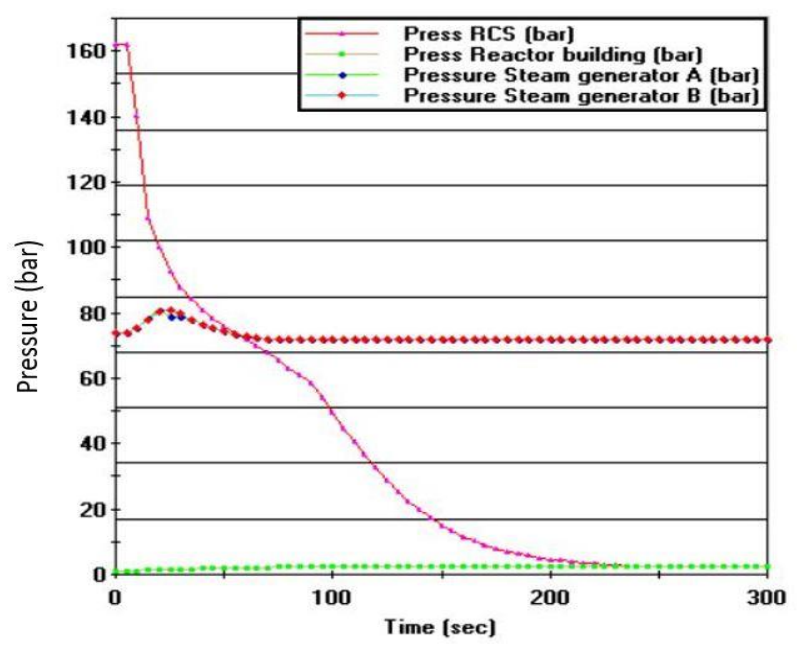

(a)

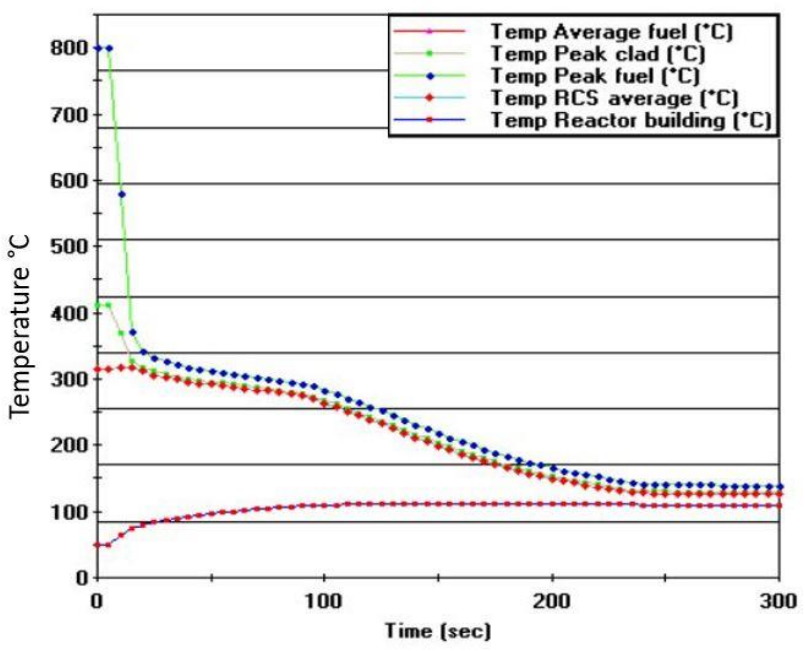

(c)

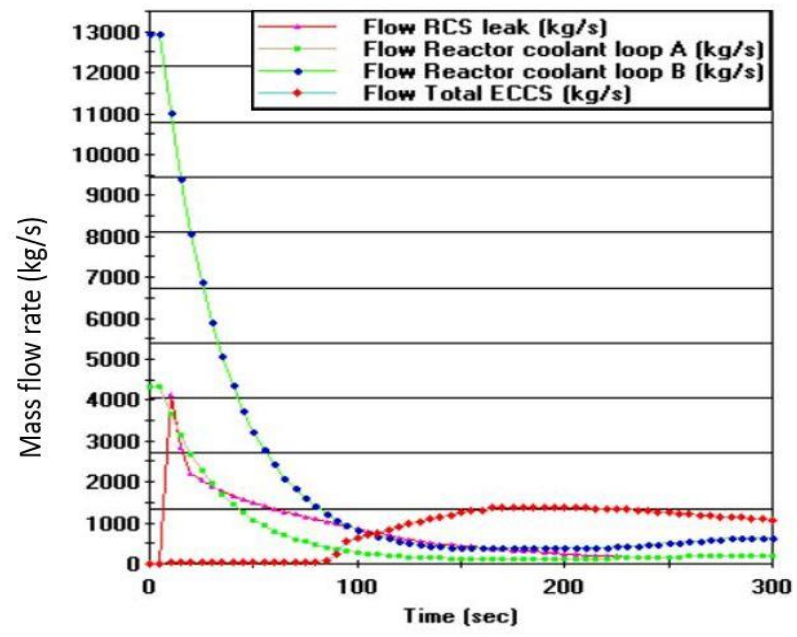

(b)

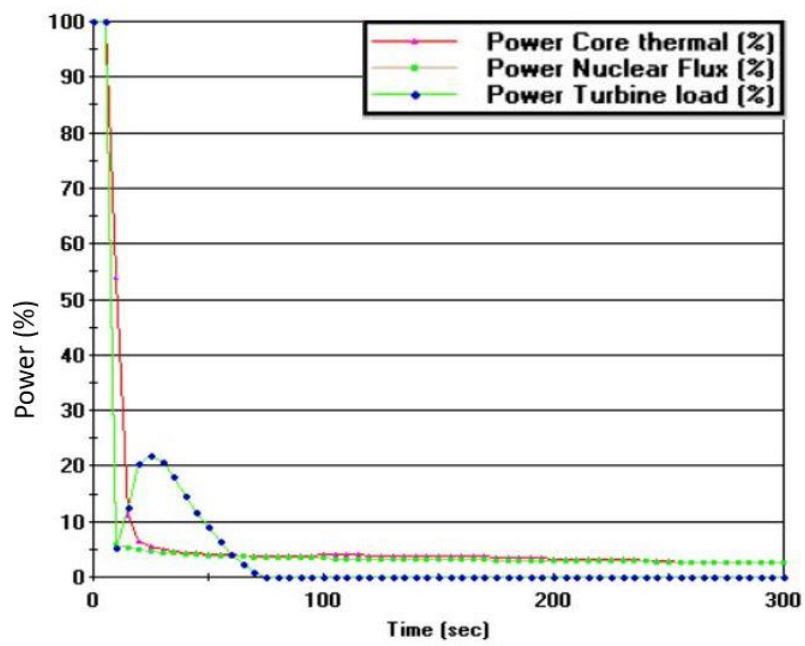

(d)

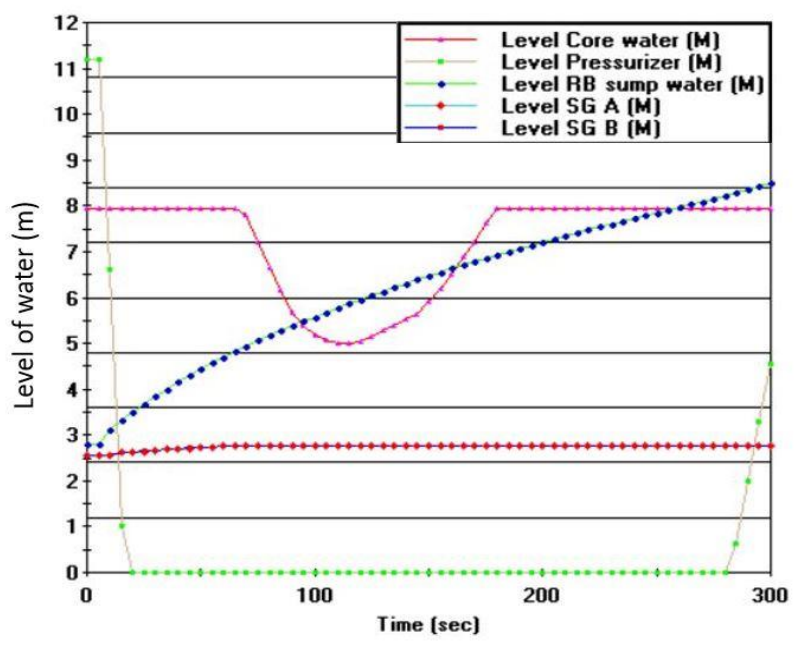

(e)

Fig. 4 (a) Pressure of RCS, RB, SGs (bar) for cold leg break (b) Mass flow rate of RCS leak, reactor coolant loops, ECCS flow water $(\mathrm{kg} / \mathrm{s})(\mathrm{c})$ Temperature of average fuel, RCS, peak clad, peak fuel, RB $\left({ }^{\circ} \mathrm{C}\right)$ for cold leg break $(\mathrm{d})$ Core thermal power $(\%)$, Nuclear flux power (\%), Turbine Load power (\%) for cold leg break (e) Water level of core, pressurizer, RB sump, SGs (m) for cold leg break. 
Fig. 3 shows that, ECCS actuated High Pressure Injection System (HPIS) at 15s when the RCS pressure was lower than the nitrogen pressure accumulator tank. Although HPIS along was not enough to compensate primary coolant loss, accumulator and Low-Pressure Injection System (LPIS) with recovery refueling water storage tank, reactor building spray help to provide boronated water. LPIS provide enough water to maintain the core submerged and responsible for long term cooling of residual heat in reactor. Compared to large break LOCA, the depressurization occurs relatively slowly in SBLOCA. Upon actuation of accumulator, ECCS water flow started to exceed the coolant discharge rate and the reactor vessel water level slowly rose again and core level water restored as illustrated in Fig. 4 (e). The RCS pressure fall down from initial steady 160 bar to about 3 bar after 200 second from the onset of accident. The Steam Generator A (SG-A) and SGB pressure initially increased after accident from 74 bar to 81 bar in 30 second for sudden loss of coolant but after 65 second both SGs reached to equivalent pressure 72 bar as shown in Fig. 4 (a). The process of depressurization was very rapid slowing down the reactor coolant leak rate. After being emptied the pressurizer during initial occurrence, RCS leak rapidly decreased as the pressure altitude change fast. RCS leak initially started after 5 seconds of the incident with $4150 \mathrm{~kg} / \mathrm{s}$ mass flow rate which slowly decreased with respect to time after 40 seconds of the accident. The leak loss of mass flow become equal with reactor coolant loop B flow at 105 seconds which was about $390 \mathrm{~kg} / \mathrm{s}$. After 220 seconds the mass flow rate become very slow but it needed more time to stop completely. ECCS started after 85 seconds with gradual mass flow rate highest of $1390 \mathrm{~kg} / \mathrm{s}$. After 245 seconds, the ECCS slow down. The reactor coolant loop A has $4300 \mathrm{~kg} / \mathrm{s}$ mass flow rate, coolant loop $\mathrm{B}$ has highest $13000 \mathrm{~kg} / \mathrm{s}$ mass flow rate which decrease very rapidly and stable in 150 seconds to 225 seconds at $390 \mathrm{~kg} / \mathrm{s}$ in Fig. 4 (b). For SBLOCA initiation reactor coolant release very high flow rate through break, which loss rate decrease due to HPIS actuation and depressurization of primary system.

In the meantime, emergency accumulator water system active to provide enough makeup water in RCS to maintain the core submerged in water so that during the transient event, fuel and cladding temperature never rise to critical value shown in Fig. 4 (c). Highest peak clad temperature and peak fuel temperature can't rise to critical value to melt the core as the control rods are fall down after $7 \mathrm{~s}$ and huge makeup water from ECCS, HPIS active due to this transient event. Fuel peak temperature, clad peak temperature, average fuel temperature falls from respectively $800^{\circ} \mathrm{C}, 415^{\circ} \mathrm{C}, 320^{\circ} \mathrm{C}$ to $150^{\circ} \mathrm{C}, 140^{\circ} \mathrm{C}$, $110^{\circ} \mathrm{C}$ after $300 \mathrm{~s}$. The sump water level in reactor building increase from $40^{\circ} \mathrm{C}$ to $100^{\circ} \mathrm{C}$ due to recirculation through RWST with LPIS. The accident is assumed to happened when the reactor operating at full $100 \%$ power. Due to the occurrence of LOCA in cold break, the simulation shows reactor trip after 40s which indicate core thermal power and nuclear flux fall to $5 \%$ and decay heat power continuously extend for next few cycles to cooled down to zero in Fig. 4 (d). The turbine load initially dropped after LOCA which increase for following 20 s and again decrease to zero as turbine trip after the malfunction.
3.2 Analysis of LOCA at cold leg without ECCS or any passive heat removal system

In VVER-1200, the emergency core cooling system is consisting with not only HPIS, but also it has LPIS, passive heat removal system, emergency accumulator water system, feed water system, reactor building spray pumps and refueling water storage tank with it to prevent all kind of accident including DBA and BDBA to tackle the situation in emergencies. Whenever ECCS face any kind of accident signal, it automatically got actuated to keep the core under water and cooled it down in order to eliminate any serious impact on the total system and environment with working personnel. When the ECCS can't operate as needed, then this scenario can turn into severe accident with core meltdown and fuel degradation.

In this case, all the ECCS equipment were disabled and reactor coolant pump was turned off manually, with a $500 \mathrm{~cm}^{2}$ LOCA in cold leg. Though, it is a hypothetical cause with unavailability of all those ECCS equipment but following the Fukushima Daiichi accident caused by earthquake and tsunami where all the emergency system failed and level/class 7 disaster happened, possible consequences of this type of accident needs to be analyzed.

For LOCA accident without enabling the ECCS, the reactor trips instantaneously and after 9 seconds all the control rods trip down to reactor core with pressurizer emptied within 20 seconds due to very rapid depressurization as shown in Fig. 5 (a). The fuel temperature continuously increases due to absent of all ECCS and passive heat removal system. With increased cladding temperature, the interaction between the cladding and steam was accelerated. Hydrogen concentration inside reactor increased with time and shortly after the core uncovery, as depicted in Fig. 5 (b) about 980 seconds after the accident, the hydrogen concentration in the reactor building exceeded 5\%. Fuel temperature increased as time goes by resulting the reactor core starts to melt. In Dose Mimic, the core melting process can be observed in Fig. 5 (c). Molten fuel collapse into the bottom of the vessel as there is nothing that can cooled the core materials. The vessel lower head may then heat up to the melting point, too. Fig. 5 (d) illustrates that, the molten debris with molten core concrete interaction with vessel penetration may drop into the containment cavity floor takes around 3000 seconds for $500 \mathrm{~cm}^{2}$ LOCA at cold leg without ECCS. During the fuel damage process, first the fission gas in the cladding may leak out. Later, if the fuel and cladding continue their degradation, radionuclides will also be released. In addition to iodine and noble gases, there are alkali metals, tellurium, barium, cerium, lanthanides, etc. The elevated concentration of these radionuclides would find their ways through the vessel break, relief valves, and containment leakage into the environment. The molten metal interacts with concrete and forms a slump. At lower temperatures, degassing of concrete occurs and both steam and carbon dioxide can be released. At higher temperatures concrete can also be molten and mixed with metals. In the event that the molten core heats up the vessel bottom and melts through it, the debris, called corium, falls into the reactor cavity. 


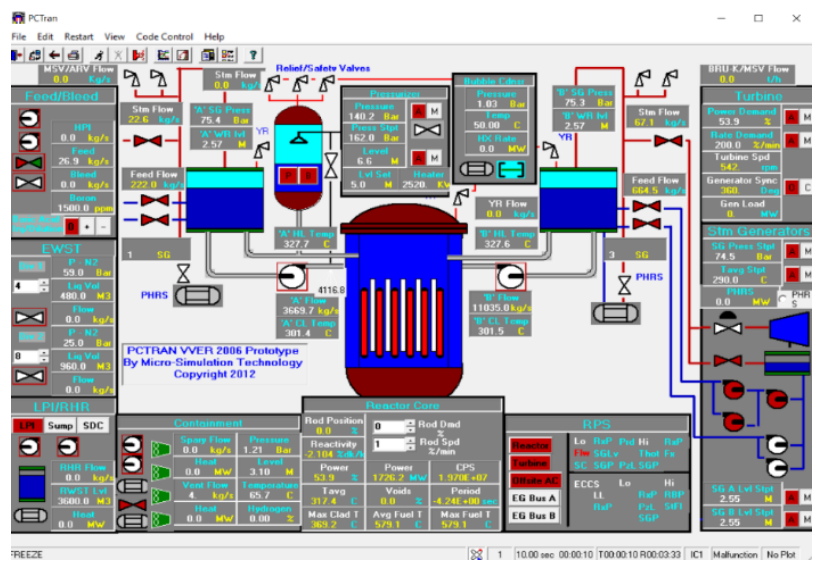

(a)

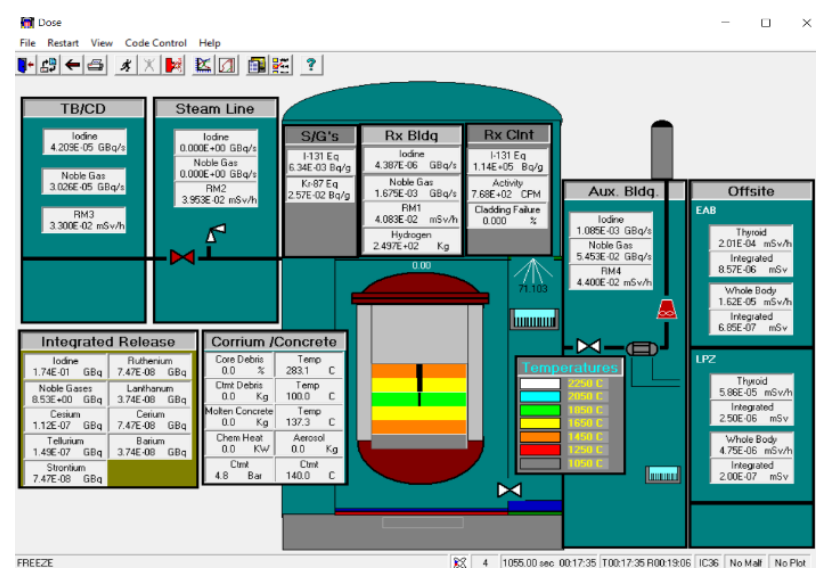

(c)

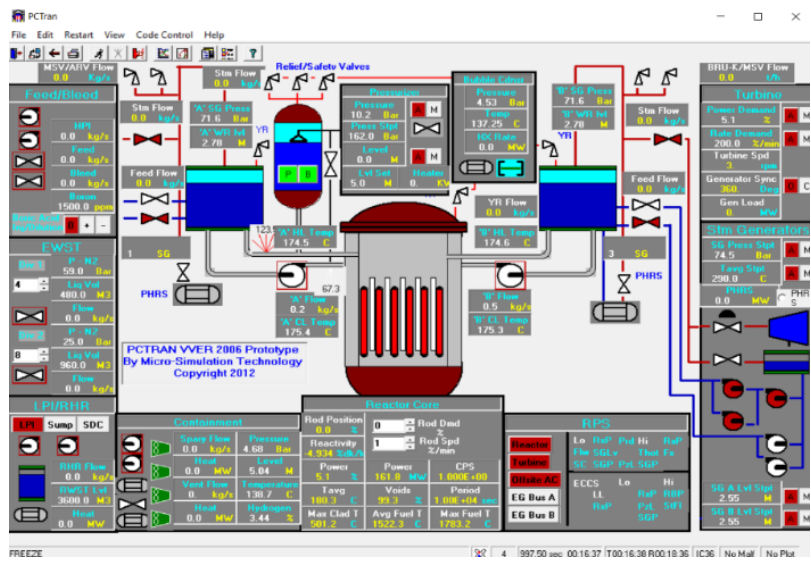

(b)

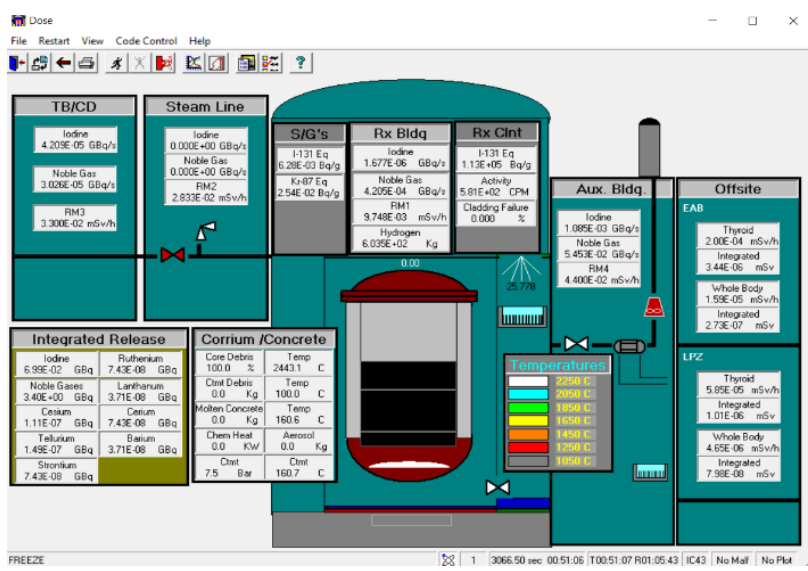

(d)

Fig. 5 Graphical user interface of PCTRAN: (a) Reactor trip for LOCA without ECCS (b) Complete core uncovery (c) Beginning of core melt (d) Molten core-concrete interaction (MCCI) with vessel penetration.

For LOCA at cold break, the reactor coolant system leak and loops fluid decrease rapidly. At the time of emptying of pressurizer in first few seconds, coolant leak rate rapidly decreased as the pressure elevation of break firstly change. From Fig. 6 (a), level of reactor building sump slowly grew up to a certain point until the recirculation process terminated and there left no water to carry the poison. Level of core water started to decrease very slowly at about 73 seconds. There created a tube rupture loop at cold leg after 350 seconds. In Fig. 6 (b), different temperatures were plotted as respect to time for initial 300 seconds. Due to increasing the sump in reactor building, temperature also increased as followed by the sump. Initially after the accident, the control rod fell down to the core but without the activity of any coolant flow inside the core, the power slowly rose by chain reaction. Before that, the core water level and control rods minimized the temperature about 140 seconds until all the remaining water vaporized totally. After the core fuel emersion, temperature rapidly increased due to unavailability of coolant. Increase in Zircaloy cladding temperature with fuel temperature accelerated the reaction between Zirconium and water. Hydrogen gas accumulation inside reactor building occurred quickly at the top of building which can get exploded when it increased to 5\%. The Zirconium cladding distortion increased very high; fraction rate about 42 in 1500 seconds whereas Hydrogen buildup was $8 \%$ at that time. DNBR or departure from nuclear boiling is the ratio of critical heat flux at specific location to operating local heat flux at that location. In all NPP, DNBR must be greater than one but it can't allow to increase more than 95. From the Fig. 6 (c), it is observed that the DNBR increased very slowly as local heat flux can't able to cross limit until all the coolant system loss and its critical value was about 80 . When the local flux was higher than critical heat flux, the core materials melted down for increasing heat flux. Fuel Doppler reactivity is the fractional change in reactivity caused by fuel temperature. Until it's less than one, there was no harm of reactivity but after explosion of the reactor building beyond 980 seconds, reactive substance released to atmosphere. As it increased after the loss of coolant accident, it progressed very much and spread radioactive materials as shown in Fig. 6 (d). Fig. 6 (e) shows the comparison between LOCA for different temperature in fuel (TF), average fuel (TAVG), peak fuel (TFPK), peak clad (TPCT) with and without ECCS for first 300s. Initially after the accident, all ECCS activated when the control rod submerged with fuel inside the core, hence temperature fell down for both conditions. But unavailability of ECCS in second case, temperature began to rise when all the water inside core vaporized and fuel with control rod became unstable due to active heat generation. 


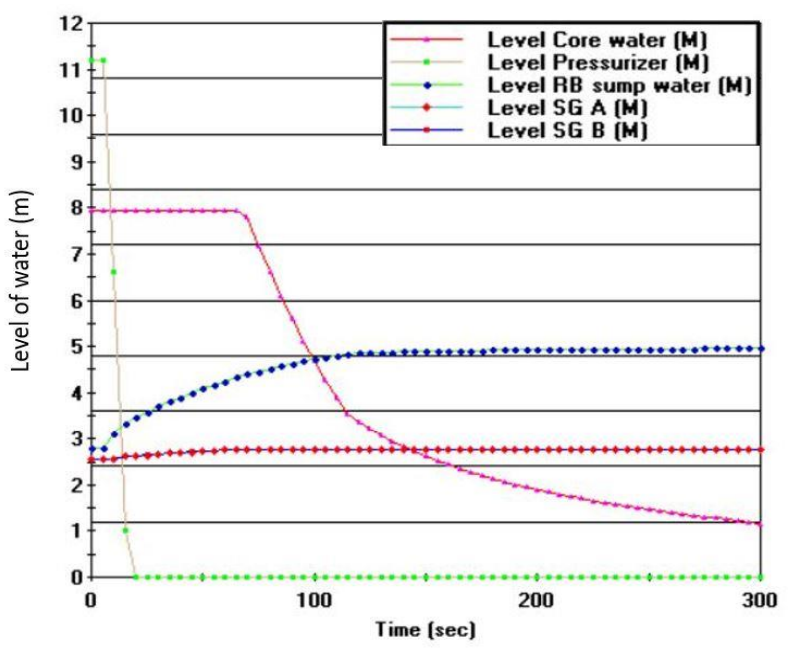

(a)

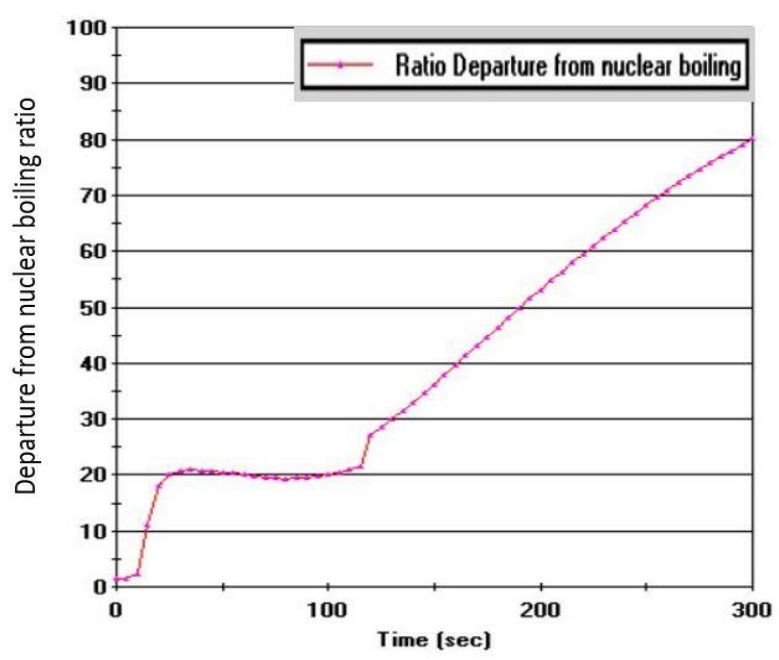

(c)

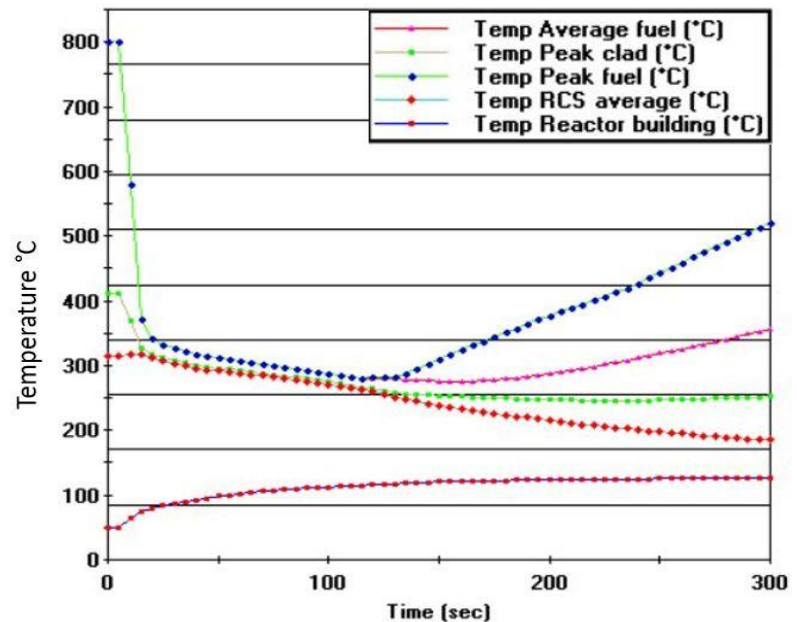

(b)

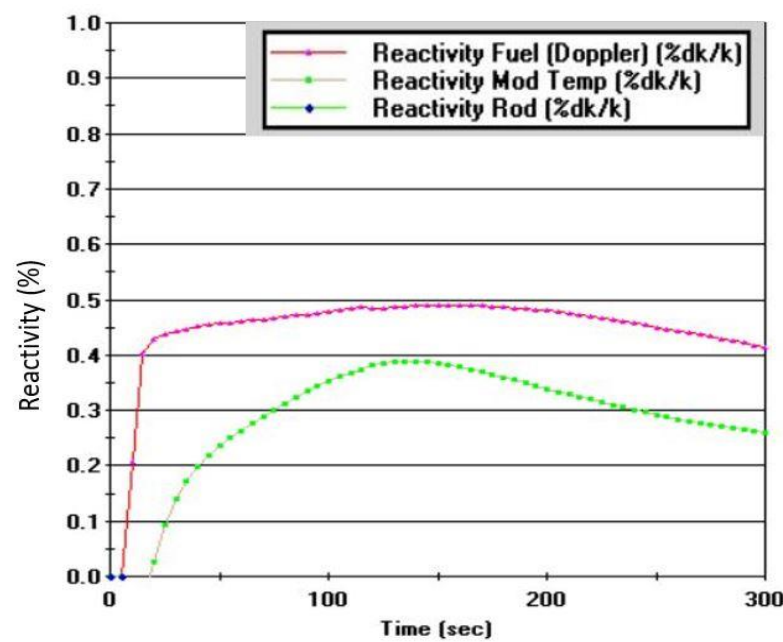

(d)

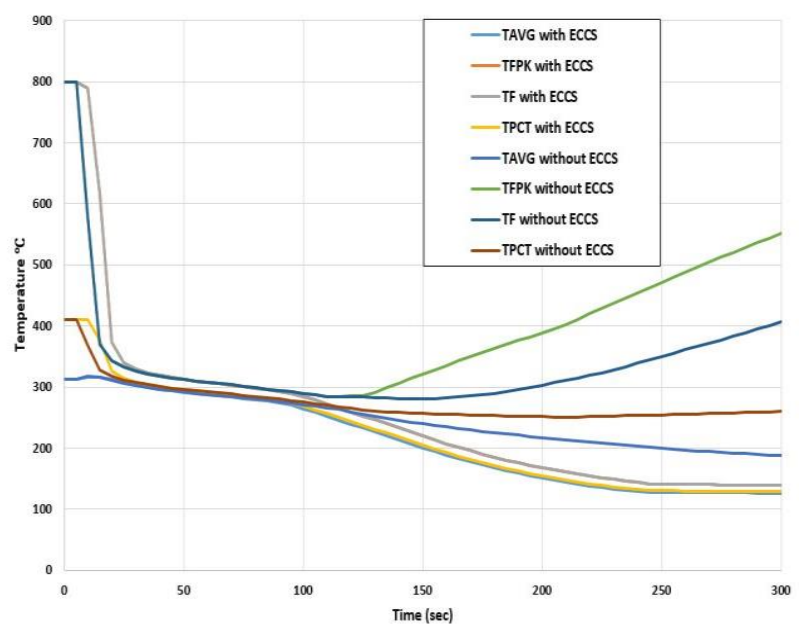

(e)

Fig. 6 (a) Level of core, pressurizer, SGs, RB sump water for LOCA at cold leg without ECCS (b) Temperature of average fuel, RCS, peak clad, peak fuel, RB $\left({ }^{\circ} \mathrm{C}\right)$ for LOCA cold leg break (c) DNBR for LOCA without ECCS (d) Fuel Doppler (\%), rod (\%), modifier reactivity (\%) for LOCA without ECCS (e) Temperature of different component with and without ECCS for LOCA at cold leg. 


\section{Conclusion}

In this study, numerical study has been conducted to investigate the different thermal hydraulics characteristics of nuclear power plant due to loss of coolant accident with and without ECCS. Loss of coolant accident may be a type of postulate event but the probability of happening it in any kind of nuclear reactor plant have enough chance due to different reasons. LOCA accident with both design basis accident analysis and beyond design basis accident analysis are employed in this paper. From the results following conclusion could be drawn:

- Design Basis Accident and Beyond Design Basis Accident both must be mitigated before they are harmful for environment and mankind. A simple Design Basis Accident can turn into serious disaster if it won't handle properly. Risk of radioactive material can be spared if proper maintenance isn't taken care off. Serious accident is not only dangerous for human, but also for every life on that area.

- Different type of thermal hydraulics behaviors like pressure, flow rate, water level in different sections, clad fuel temperature, feed water cooling system, power and many things can be investigated through LOCA analysis. From numerical simulation for LOCA without ECCS transient behaviors and core degradation dose mimic it is found that it takes 3066 seconds to complete core meltdown for $500 \%$ area or $(25.23 \mathrm{~cm}$ diameter $)$ failure fracture. Different arbitrary failure fraction takes different time to conclude in MCCI but reactivity release must be controlled. Design basis LOCA show good agreements with Primary Safety Analysis Safety report (PSAR) but in case of BDB LOCA occurring without ECCS, the core melting process is not able to mitigate the accident.

\section{References}

[1] Gidropress. "Status report 108 - VVER-1200 (V491),https://aris.iaea.org/PDF/VVER-1200(V491).pdf' '2011,Advanced Reactors Information System (ARIS).

[2] Gidropress. "Status report 107 - VVER-1200 (V-392M), https://aris.iaea.org/PDF/VVER-1200(V-392M).pdf"' 2011 Advanced Reactors Information System (ARIS).
[3] C. VITANZA, "DISCUSSION ON EXPERIMENTAL METHODS TO DERIVE LOCA SAFETY LIMIT" Journal: 經濟研究, 2018, Session 3, pages 224-232.

https://wwwpub.iaea.org/MTCD/publications/PDF/te_13 20_web/t1320_part2.pdf

[4] Ghafari, M., Ghofrani, M.B. and D'Auria, F., 2018. Boundary identification between LBLOCA and SBLOCA based on stratification and temperature gradient in twophase PTS. Annals of Nuclear Energy, 115, pp.430-441.

[5] Mollah, A.S., 2018. PCTRAN: Education Tool for Simulation of Safety and Transient Analysis of a Pressurized Water Reactor. International Journal of Integrated Sciences and Technology, 3, pp.1-10.

[6] Ibrahim, S.J., Ewim, D.R. and Edeoja, O.A., 2013. Simulation of Safety and Transient Analysis of a Pressurized Water Reactor using the Personal Computer Transient Analyzer. Leonardo Electronic Journal of Practices and Technologies, 22, pp.93-105.

[7] Cheng, Y.H., Shih, C., Jiang, S.C. and Weng, T.L., 2008. Development of accident dose consequences simulation software for nuclear emergency response applications. Annals of Nuclear Energy, 35(5), pp.917926.

[8] Cheng, Y.H., Shih, C., Jiang, S.C. and Weng, T.L., 2008. Improvement of accident dose consequences simulation software for nuclear emergency response applications. Annals of Nuclear Energy, 35(10), pp.18641877.

[9] Khan, A.H. and Islam, M.S., 2019. A Pctran-Based Investigation On The Effect Of Inadvertent Control Rod Withdrawal On The ThermalHydraulic Parameters Of A Vver-1200 Nuclear Power Reactor. Acta Mechanica Malaysia (AMM), 2(2), pp.32-38.

[10]Fyza, N., Hossain, A. and Sarkar, R., 2019. Analysis of the thermal-hydraulic parameters of VVER-1200 due to loss of coolant accident concurrent with loss of offsite power. Energy Procedia, 160, pp.155-161.

[11] Saha, A., Fyza, N., Hossain, A. and Sarkar, M.R., 2019. Simulation of tube rupture in steam generator and transient analysis of VVER-1200 using PCTRAN. Energy Procedia, 160, pp.162-169. 